\title{
Experimental evidence for apical dominance in the seagrass Cymodocea nodosa
}

\author{
J. Terrados ${ }^{1, *}$, C. M. Duarte ${ }^{1}$, W. J. Kenworthy ${ }^{2}$ \\ 'Centro de Estudios Avanzados de Blanes, C.S.I.C., Cami de Santa Bárbara, s/n, E-17300 Blanes (Girona), Spain \\ ${ }^{2}$ Beaufort Laboratory, Southeast Fisheries Science Center, National Marine Fisheries Service, NOAA, Beaufort, \\ North Carolina 28516-9722, USA
}

\begin{abstract}
The existence of apical dominance in the seagrass Cymodocea nodosa (Ucria) Ascherson was elucidated by in situ experimental manipulation. Removal of the apical meristem of a $C$. nodosa horizontal rhizome promoted an increase in the branching rate of the rhizome which was mostly driven by a change in the growth form of the nearest vertical rhizome into horizontal growth. Although the elongation of the branches increased when the rhizome apical meristem was eliminated, total plant growth was reduced by severing of the apical meristem.
\end{abstract}

KEY WORDS: Seagrass Apical dominance Cymodocea nodosa

\section{INTRODUCTION}

The vegetative development and proliferation of most seagrasses is, as in other clonal angiosperms, greatly dependent on the activity of apical meristems (Tomlinson 1974). Differential rates of meristematic activity are responsible for the dichotomy between horizontal and vertical growth of seagrass. Some seagrass species have meristems which slow their growth during winter or remain dormant when disturbed, thus leaving semi-permanent markers of seasonal growth activity that can be used to reconstruct the plant's growth history (Caye \& Meinez 1985, Gallegos et al. 1993, Duarte et al. 1994). Growth of these dormant meristems is reactivated when either the environmental stress factors or the physiological inhibitors are relaxed, which allows the plant to adapt to environmental fluctuations (Tomlinson 1974, Caye \& Meinesz 1985).

In many clonal plants meristem activity is controlled by the process of apical dominance, which refers to the inhibitory influence that the growing apical meristem exerts on the lateral meristems, preventing or slowing

•E-mail: terrados@ceab.es down their development (Salisbury \& Ross 1992). In addition to physical damage caused by herbivory or bioturbation, other external factors such as the quality and quantity of light, and the density of neighbouring shoots can affect meristematic activity (Aarssen 1995). It is generally accepted that internal controls on lateral meristems are effected by plant growth regulators (auxins, cytokinins; Martin 1987), although nutrient availability might also have a role (Cline 1991). Thus, elucidation of the controls on meristem activity is essential to understanding seagrass vegetative development and productivity.

The vegetative development of Cymodocea nodosa (Ucria) Acherson is the result of the activity of a leafy apical meristem that produces a horizontal rhizome (main axis) with long internodes and a lateral meristem at each node (see Fig. 1A, B, C) (Bornet 1864, Tomlinson 1974, Caye \& Meinesz 1985). During the most active period of the growing season, lateral meristems show immediate development into vertical rhizomes with short internodes and a leaf bundle at the apex. These lateral meristems may form additional branches, which also grow vertically, or change their growth form into that of a horizontal rhizome, which provides an important source of new shoots, lateral coverage, 


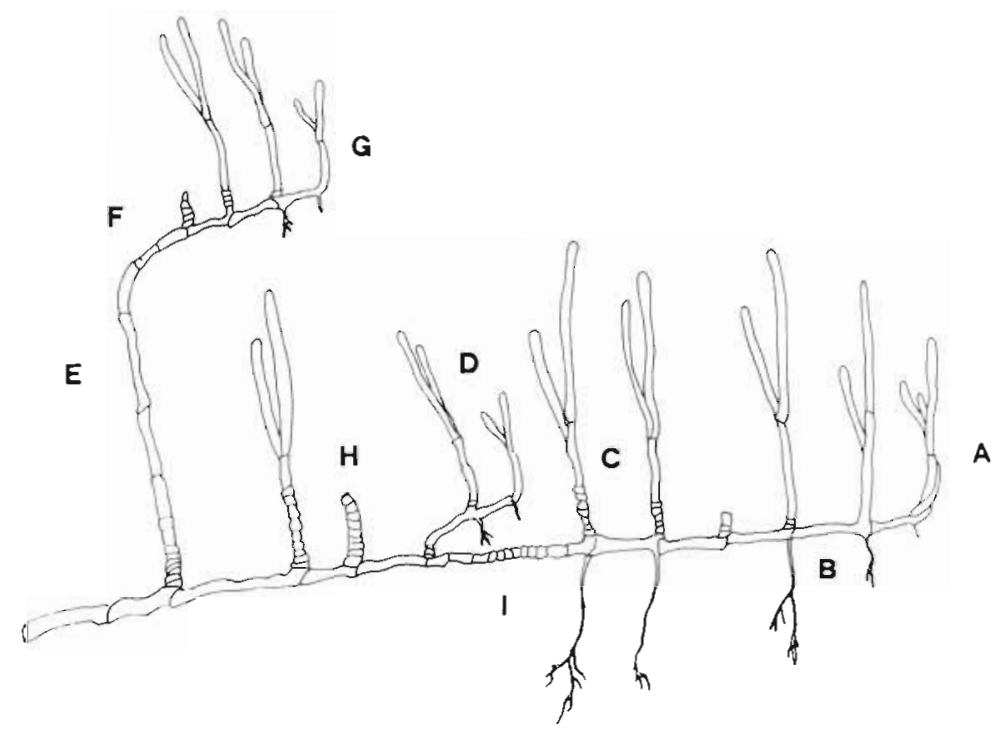

Fig. 1 lllustration of the growth form of Cymodocea nodosa showing: (A) leafy apical meristem on the main horizontal rhizome axis (the experimental treatment consisted in the ellimination of this apical meristem). (B) horizontal rhizome internode, (C) lateral meristems with short vertical rhizome internodes, (D) lateral meristem with horizontal rhizome growth, (E) vertical rhizome growth with long internodes, $(F)$ transition from vertical to horizontal rhizome growth, (G) horizontal rhizome with vertical lateral meristems, (H) dead vertical shoot, (I) short winter internodes

\section{MATERIAL AND METHODS}

The study was conducted on a shallow (<0.5 m depth) sandy platform occupied by a patchy meadow of Cymodocea nodosa (Ucria) Ascherson (Duarte \& Sand-Jensen 1990). The site is on the bay side of the sand spit that separates the Alfacs Bay from the Mediterranean in NE Spain $\left(40^{\circ} 36.15^{\prime} \mathrm{N}\right.$, $0^{\circ} 43.08^{\prime} \mathrm{E}$ ). On 21 June 1995, 80 horizontal rhizomes of $C$. nodosa were haphazardly selected at the edge of 5 different meadow patches (size about 32 to $64 \mathrm{~m}^{2}$; Duarte \& Sand-Jensen 1990). Each patch was designated as an experimental block, and experimental treatments were haphazardly assigned to individual rhizome apices that grew outward at the patch edge ('runners'). The experiment compared control plants (intact runners) with treatment plants (runners with the apical meristem removed with scissors). Before severing the rhizome apex, the position number of nodes from the apex) and length $(\mathrm{cm})$ of all branches present between the apex and the 11 th shoot on the rhizome (about $0.5 \mathrm{~m}$ from the apex) were recorded. A fluorescent-painted plas-

and expansion of the clone (Fig. 1D). We hypothesised that the change in the growth form of a lateral meristem from vertical to horizontal is controlled by apical dominance. In contrast, in winter, meristematic activity is greatly reduced, rhizome internodes are shortened, and the lateral meristems abort (Fig. $1 \mathrm{H}, \mathrm{I}$ ).

While the presence of lateral meristems has been reported for most seagrass genera, evidence for control of their growth by apical dominance is largely observational. Damage to main rhizome apices is presumed to encourage rhizome branching in Amphibolis and Syringodium (Tomlinson 1974, Bell \& Tomlinson 1980), but the control mechanism has not been experimentally tested. The presence of apical dominance can be tested for by examining whether the experimental elimination of the apical meristem promotes activity of suppressed lateral meristems. This could result in a shift in the growth form of vertical rhizomes into horizontal rhizomes, increased branching of the horizontal rhizomes, and/or increased growth of any rhizome branches already present, either horizontal or vertical.

Here we report experimental evidence of the presence of apical dominance in a population of the Mediterranean seagrass Cymodocea nodosa (Ucria) Ascherson growing in northeast Spain. In particular, we report the response of rhizome branching rate and branch elongation to removal of the main horizontal rhizome apical meristem. tic cable tie label was placed on the 12 th internode of the rhizome. The plants were not disturbed in any other way. Forty runners (replicates) were assigned to each treatment, representing a total of 80 rhizomes distributed in 5 blocks of 16 rhizomes each. The blocks were 20 to $40 \mathrm{~m}$ apart from each other.

After 57 d (17 August 1995), runners were located and carefully harvested by excavating the entire rhizome segment with shoots and lateral branches. Not all of the 80 runners could be located at the time of harvest. The resulting number of replicates was 20 control and 30 treatment plants. The individual runners were placed inside plastic bags and morphometric measurements were carried out within the next $3 \mathrm{~d}$. Positions (relative to the position of the rhizome apex at the time the experiment was set) of new horizontal rhizome branches on the main axis were recorded, as well as the length $(\mathrm{cm})$ and number of living and dead shoots. The length $(\mathrm{cm})$ and the number of living and dead shoots of all the branches present at the the start of the experiment were recorded again to estimate their growth during the experimental period. We additionally recorded length $(\mathrm{cm})$, biomass (dry weight, after $65^{\circ} \mathrm{C}$ for $24 \mathrm{~h}$ ), number of internodes, and number of living and dead shoots of newly formed parts of the main rhizome axis of control plants. The specific weight of the rhizome was estimated as the dry weight per length unit $(\mathrm{cm})$. In treatment plants the same vari- 
ables were recorded for the new horizontal rhizome branch showing the largest growth (the new main axis).

Differences between treatments in the response variables were tested using either the Student's t-test or the non-parametric $U$-test of Mann-Whitney (Sokal \& Rohlf 1981). Differences in the growth of the branches situated at different positions on the rhizome were tested using the Kruskal-Wallis $(H)$ non-parametric ANOVA (Sokal \& Rohlf 1981).

\section{RESULTS}

Most of the treatment plants formed a new branch behind the excised apex; this new, horizontally growing branch takes over the function of the old main rhizome which does not have the ability for active growth any more. The branches on the main rhizome axis were located 8 or more nodes away from the original thizome apex in both control and treatment plants at start of the experiment (Fig. 2A). The elimination of the apical meristem on a horizontal rhizome promoted a shift in the growth form of the first vertical rhizome into a horizontal growing rhizome: 21 out of the 30 treatment plants had a new branch with a horizontal growth form on the 2 nd node behind the original position of the rhizome apex, whereas only 1 out of the 20 control plants had a branch at that node (Fig. 2A, B). This response also occurred at the 3rd node on the rhizome, but with a lower frequency. In the control plants the number of new branches appeared to increase as the distance from the original apex increased (Fig. 2B), in contrast to the dominance of branches at 1 or 2 nodes from the position of the removed apex in the treatment plants (Fig. 2B).

The elimination of the apical meristem increased the branching rate of the main rhizome (Table 1), this increase being mostly driven by the new branches produced at the 2 nd node (Fig. 2B). There was no evidence of increased branching at nodes situated further away from the original apex $(t=0.5506, \mathrm{df}=47, \mathrm{p}=0.5845 ;$ branch data at 2 nd node excluded from the analysis). The growth in length of the branches including both those pre- sent at the start of the experiment and the new ones) was also higher in the treatment than in the control plants (Table 1, Fig. 2C). In control plants the growth in length of the branches was similar at all the nodes along the rhizome, while in treatment plants the growth was higher at the 2 ends of the rhizome than at central nodes (Kruskal-Wallis $H=22.2642, \mathrm{p}=0.0045$ ) (Fig. 2C). The number of living shoots on the new branches of treatment plants was 3 times higher than that of control plants (Table 1). However, the percentage of dead shoots in the new branches formed during the experiment (relative to the total amount of leaf shoots produced by the branch) was similar in both control and treatment plants (Table 1).

The growth performance of the main rhizome in control plants was higher than that of the new main horizontal rhizome of the growing branch produced on treatment plants: the number of horizontal rhizome internodes produced, their size (length and weight),

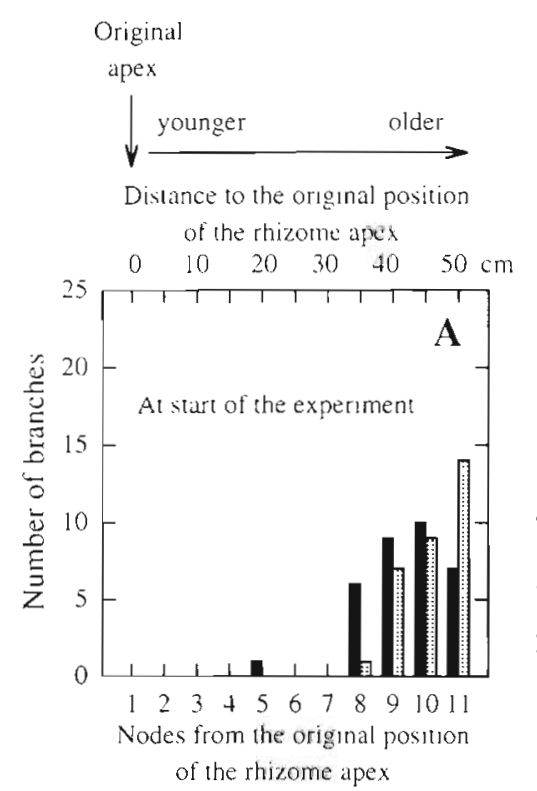

Distance to the original position of the rhizome apex

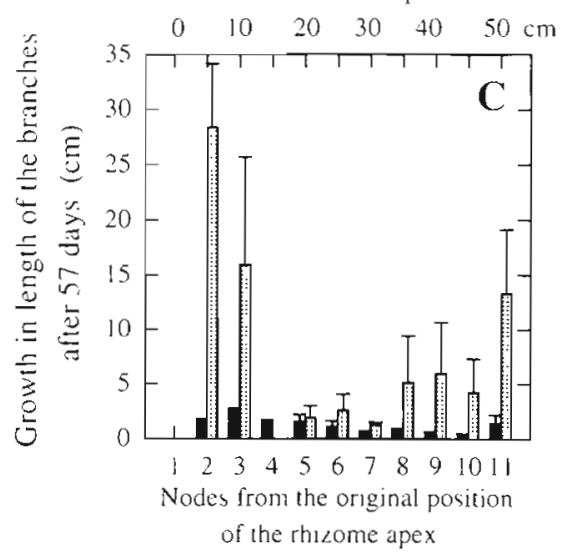

Control plants Treatment plants

Distunce to the original posstion of the rhizome apex

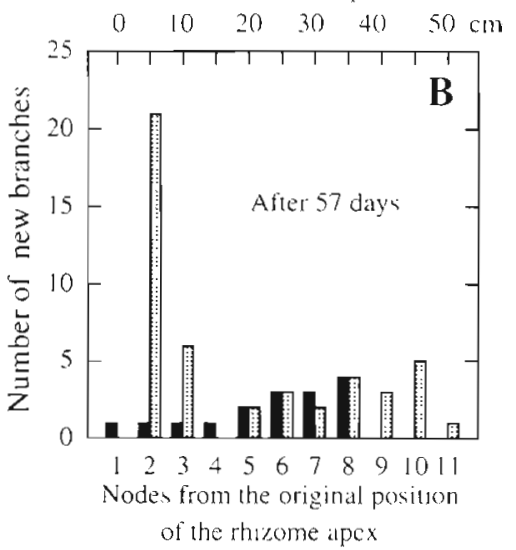

Fig. 2. Cymodocea nodosa. (A) Number of branches at the start of the experiment (21 June 1995). and $(B)$ number of new branches produced by control and treatment plants during the experiment. (C) Growth in length $(\mathrm{cm}$, after $57 \mathrm{~d})$ of the branches located in the old portion of the main rhizome axis of control and treatment plants during the experiment (bars represent $+1 \mathrm{SE})$. Numbers on $x$-axis give the position of the branches (expressed as nodes) relative to the original apex and the distance $(\mathrm{cm})$ to the original position of the rhizome apex 
Table 1 Cymodocea nodosa. Morphometric features of the old portion (that present at the time the experiment was initiated) of the main horizontal rhizome axis of control and treatment plants. Differences were tested using either the Student's $t$-test or the non-parametric $U$-test of Mann-Whitney. n: number of plants or branches measured

\begin{tabular}{|c|c|c|c|c|c|c|c|}
\hline \multirow[t]{2}{*}{ Response variable } & \multicolumn{3}{|c|}{ Control plants } & \multicolumn{3}{|c|}{ Treatment plants } & \\
\hline & Mean & $(\mathrm{SD})$ & $\mathrm{n}$ & Mean & $(S D)$ & $n$ & \\
\hline New branches per plant & 0.75 & $(1.33)$ & 20 & 1.62 & $(1.32)$ & 29 & $t=2.2599, \mathrm{df}=47, \mathrm{p}=0.0285$ \\
\hline $\begin{array}{l}\text { Growth in length of the } \\
\text { branches (cm after } 57 \mathrm{~d} \text { ), } \\
\text { both old and new }\end{array}$ & 0.86 & $(1.02)$ & 47 & 13.44 & $(21.46)$ & 77 & $U=763.0, p<0.0001$ \\
\hline $\begin{array}{l}\text { Number of living } \\
\text { shoots per branch on } \\
\text { new branches only }\end{array}$ & 2.00 & $(0.55)$ & 14 & 6.11 & $(4.81)$ & 46 & $U=83.0, \mathrm{p}<0.0001$ \\
\hline $\begin{array}{l}\text { Percentage of dead } \\
\text { shoots per branch on } \\
\text { new branches only }\end{array}$ & 7.14 & $(18.16)$ & 14 & 2.74 & $(10.20)$ & 46 & $U=301.0, p=0.7136$ \\
\hline
\end{tabular}

Table 2. Cymodocea nodosa. Morphometric features of the new portion (that produced during the experiment) of the main horizontal rhizome axis of control and treatment plants (for treatment plants data are based on the new main axis formed after elimination of the apical meristem). Differences were tested using the Student's t-test or the non-parametric U-test of Mann-Whitney. n: number of plants measured

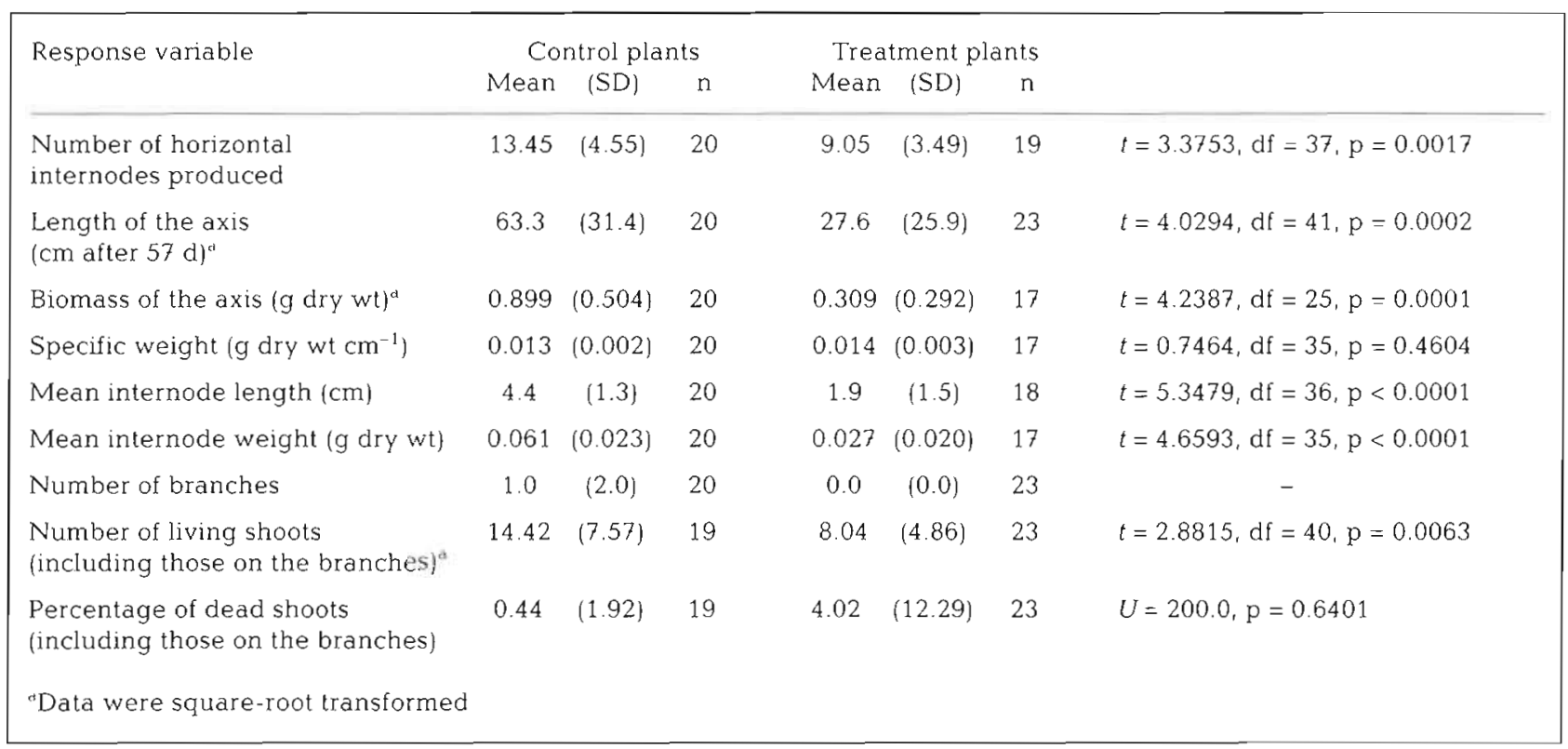

and the number of shoots produced were all higher in the control than in treatment plants (Table 2). There was no difference, however, in the specific weight ( $g$ of dry weight per $\mathrm{cm}$ of rhizome) of the horizontal rhizome between control and treatment plants. Control plants had produced, on average, 1 branch in the new portion of the main rhizome, while treatment plants did not produce any (Table 2). These new branches were situated between 6 and 12 nodes away from the rhizome apex.

The total growth in length of each plant was calculated as the sum of the growth of the branches in the old portion of the rhizome plus, in the case of control plants, the growth of the main axis. Although branch growth was higher in treatment than in control plants (Table 1, Fig. 2C), total growth of the plant was still higher in the control plants (Fig. 3).

\section{DISCUSSION}

Our results provide evidence of the existence of apical dominance in a marine angiosperm. Elimination of the apical meristem of Cymodocea nodosa horizontal 


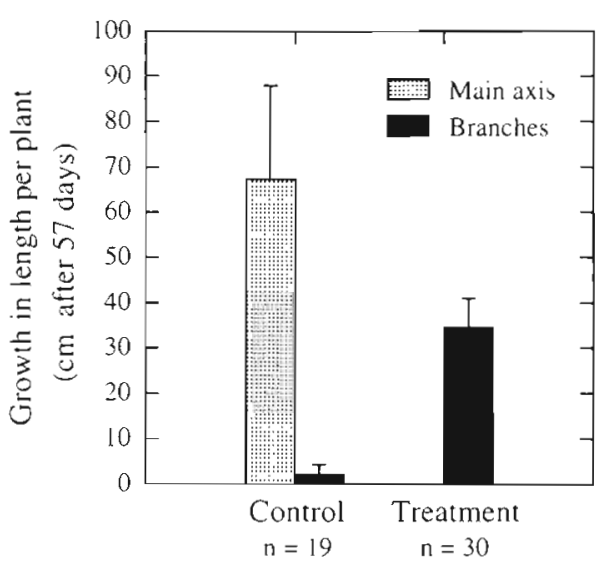

Fig. 3. Cymodoced nodosa. Total growth in length (cm, after $57 \mathrm{~d}$ ) of the rhizome of control and treatment plants, and its partition between the main rhizome axis and the branches. Bars represent +1 SE. n: number of replicates

rhizomes promoted a change in the growth form of the closest vertical rhizome into horizontal growth (Fig 2B). This effect was also evident, although attenuated, in the second closest vertical rhizome. These results, therefore, confirm previous suggestions based on field evidence for this seagrass (Caye \& Meinesz 1985) and define the spatial scale of this effect.

The increased branching of the main rhizome of the treatment plants was driven by the change in the growth form of the closest vertical shoots. The differences in the number of new branches per plant were non-significant when data from the 2nd node were excluded from the analysis. This branching response of Cymodocea nodosa results, then, in the replacement of the damaged meristem and maintenance of the general plant form ('regenerative' branching; Tomlinson 1974), and did not result in an increase in the number of apical meristems ('proliferative' branching; Tomlinson 1974). A similar response has also been suggested for Syringodium (Tomlinson 1974). Change in the growth form of the nearest vertical rhizome into horizontal growth is a compensatory mechanism by which damaged apical rhizome meristems are replaced after disturbance and, therefore, the number of actively growing horizontal rhizomes is maintained.

Further evidence of the existence of apical dominance in Cymodocea nodosa is provided by the increased elongation of the branches in the treatment plants (Fig. 2C). This suggests that the presence of the apical meristem also has an inhibitory effect on growth of lateral branches. It has been suggested that plants with a 'guerrilla' growth strategy (Lovett-Doust 1981), like C. nodosa, would benefit from having a strong apical dominance through reduction of ramet interference and promotion of habitat 'exploration' and resource acquisition in resource-poor environments (Aarssen 1995).
Rhizome elongation supported by the apical meristems of control plants was twice that achieved by the apical meristems of the new main axes in treatment plants (Fig. 3). The control main axis produced numerically more and longer internodes than that of the treatment plants. In addition, treatment plants did not produce any branches in the new main horizontal rhizomes while control plants did (Table 2). The production of fewer internodes by the new main axes of treatment plants may be related to the time needed for the plant to recover from disturbance caused by elimination of the apical meristem. The smaller size of the internodes on the treatment plants might be a consequence of intraplant competition for resources, as other branches in the rhizome had also increased growth (Fig. 2c). Total plant growth, however, was smaller in treatment than in control plants (Fig. 3) and suggests that the simple partition of resources between competing meristems cannot completely explain the increased growth of the branches in the old portion of the plant, or the reduced growth of the new main rhizome in the treatment plants.

Our results indicate the importance of apical dominance in Cymodocea nodosa as a mechanism controlling the growth form of vertical rhizomes and the suppresion of the growth of lateral branches. Due to the clonal nature of seagrasses, the shoots situated near the rhizome apex are younger than those situated further away. Therefore the physical distance between any 2 connected shoots is paralleled by an age difference between them (Duarte et al. 1994). The results obtained indicate that the inhibitory effect of the apical meristem on the development of lateral meristems is effective on meristems located within 6 to 8 internodes (i.e. within $0.5 \mathrm{~m}$ ) from the rhizome apex. We noted, however, that the inhibitory effect of the apical meristem on the growth of the lateral branches is actually effective at greater distances (about $1 \mathrm{~m}$ ), because the growth of the lateral branches of control plants remained depressed despite their increasing distance from the apical meristem as the rhizomes grew along during the experiment. These results provide evidence of the existence of clonal integration in C. nodosa at distances $\leq 0.5$ to $1 \mathrm{~m}$, and also help define the period of time (at least 3 to 4 mo during the growing season) during which the apical meristem exerts an effective control on the vegetative development of the lateral meristems.

Acknowledgements. This study was funded by the project AMB94-0746 of the Spanish Interministerial Commission of Science and Technology (CICYT). W.J.K. was supported by the sabbatical program of the Ministry of Education and Science of Spain. We thank Joyce S. Salita-Espinosa, Rui Santos and María del Carmen Sánchez for their help during the fieldwork. 


\section{LITERATURE CITED}

Aarssen LW (1995) Hypothesis for the evolution of apıcal dominance in plants: implications for the interpretation of overcompensation. Oikos 74:149-156

Bell AD, Tomlinson PB (1980) Adaptive architecture in rhizomatous plants. Bot J Linn Soc 80:125-160

Bornet E (1864) Recherches sur le Phucagrostis major Cavol. Ann Sci Nat 5, Ser Bot 1.:5-51

Caye G. Meinesz A. (1985) Observations on the vegetative development, flowering and seeding of Cymodocea nodosa (Ucria) Ascherson on the mediterranean coasts of France. Aquat Bot 22:277-289

Cline MG (1991) Apical dominance. Bot Rev 57:318-358

Duarte CM, Marbá N, Agawin NSR, Cebrián J, Enriquez S, Fortes MD, Gallegos ME, Merino $M$, Olesen B, SandJensen K, Uri JS, Vermaat JE (1.994) Reconstruction of seagrass dynamics: age determinations and associated tools for the seagrass ecolugist. Mar Ecol Prog Ser 107 . $195-209$

This article was submitted to the editor
Duarte CM, Sand-Jensen K (1990) Seagrass colonization patch formation and patch growth in Cymodocea nodosa. Mar Ecol Prog Ser 65:193-200

Gallegos ME, Merino M, Marbá N, Duarte CM (1993) Biomass and dynamics of Thalassia testudinum in the Mexican Caribbean: elucidating rhizome growth. Mar Ecol Prog Ser 95:185-192

Lovett-Doust L (1981) Population dynamics and local specialization in a clonal perennial (Ranunculus repens) I. The dynamics of ramets in contrasting habitats. J Ecol 69: $743-755$

Martin GC (1987) Apical dominance. Hortscience 22:824-833

Salisbury FB, Ross CW (1992) Plant physiology. Wadsworth, Belmont, $C A$

Sokal RR, Rohlf FJ (1981) Biometry. The principles and practice of statistics in biological research. WH Freeman and Co, New York

Tomlinson PB (1974) Vegetative morphology and meristem dependence-the foundation of productivity in seagrasses. Aquaculture 4:107-130

Manuscript first received: October 29, 1996

Revised version accepted: February 3, 1997 